\title{
ULAM-HYERS-RASSIAS STABILITY OF A NONLINEAR STOCHASTIC ITO-VOLTERRA INTEGRAL EQUATION
}

\author{
Ngo Phuoc Nguyen Ngoc and Nguyen VAN VinH
}

Abstract. In this paper, by using the classical Banach contraction principle, we investigate and establish the stability in the sense of Ulam-Hyers and in the sense of Ulam-Hyers-Rassias for the following stochastic integral equation

$$
X_{t}=\xi_{t}+\int_{0}^{t} A\left(t, s, X_{s}\right) d s+\int_{0}^{t} B\left(t, s, X_{s}\right) d W_{s},
$$

where $\int_{0}^{t} B\left(t, s, X_{s}\right) d W_{s}$ is Ito integral.

Mathematics subject classification (2010): Primary 60H20, 34K20; Secondary 47H10.. point theorem.

Keywords and phrases: Ulam-Hyers-Rassias stability, Stochastic integral equations, Banach's fixed

\section{REFERENCES}

[1] M. Ak Kouchi, A. Bounabat, M. H. L. Rhali, Fixed point approach to the stability of an integral equation in the sense of Ulam-Hyers-Rassias, Annales Mathematicae Silesianae 25 (2011), 27-44.

[2] T. AOKI, On the stability of the linear transformation in Banach spaces, J. Math. Soc. Japan. 2 (1950), 64-66.

[3] J. A. BAKER, The stability of certain functional equations, Proceedings of The American Mathematical Society, Volume 112, Number 3, July 1991.

[4] N. B. Bellout, J. BRZDeK, K. CiePlins Ki, On some recent developments in Ulam's type stability, Abstract and Applied Analysis, Volume 2012, Article ID 716936, 41 pages.

[5] L. P. CASTRO, D.A. Ramos, Hyers-Ulam-Rassias stability for a class of nonlinear Volterra integral equations, Banach J. Math. Anal. 3, 1 (2009), 36-43.

[6] L. CǍDARIU, V. RADU, Fixed points and the stability of Jensen's functional equation, J. Inequal. Pure Appl. Math. 4, 1 (2003), Art. ID 4.

[7] Y. J. Cho, Th. M. Rassias, R. SAadati, Stability of functional equations in random normed spaces, Springer, 2013.

[8] D. H. HYERS, On the stability of linear functional equation, Proc. Natl. Acad. Sci. USA 27 (1941), $222-224$.

[9] D. H. Hyers, G. Is AC, TH. M. RAssias, Stability of functional equation in several variables, Birkhäuser, Basel, 1998.

[10] I. ITO, On the existence and uniqueness of solutions of stochastic integral equations of the Volterra type, Kodai Math. J. 2 (1979), 158-170.

[11] S. M. JUNG, A fixed point approach to the stability of a Volterra integral equation, Fixed Point Theory and Applications, Vol. 2007, 9 pages.

[12] S. M. JUnG, Hyers-Ulam-Rassias stability of functional equations in nonlinear analysis, Springer, 2010.

[13] S. M. JUnG, A fixed point approach to the stability of differential equations $y^{\prime}=F(x, y)$, Bull. Malays. Math. Sci. Soc. (2) 33, 1 (2010), 47-56.

[14] H. A. Kenary, S. Y. Jang, C. PARK, A fixed point approach to the Hyers-Ulam stability of a functional equation in various normed spaces, Fixed Point Theory and Applications, December 2011, 2011:67. 
[15] H. H. KUO, Introduction to stochastic integration, Springer, 2006.

[16] T. MiURA, S. MiYaJima, S. E. TAKAhasi, A characterization of Hyers-Ulam stability of first order linear differential operators, J. Math. Anal. Appl. 286, 1 (2003), 136-146.

[17] T. MiURA, S. MiYAJIMA, S.-E. TAKAHASI, Hyers-Ulam stability of linear differential operator with constant coefficients, Math. Nachr. 258 (2003), 90-96.

[18] N. P. N NGOC, Ulam-Hyers-Rassias stability of a nonlinear stochastic integral equation, Differential equations \& Applications, 9, 2 (2017), 183-193.

[19] B. ØKSEndal, Stochastic Differential Equations, Springer-Verlag Heidelberg New York, Fifth Edition.

[20] W. J. Padgett, A. N. V RaO, Solution of a stochastic integral equation using integral contractors, Information and Control 41 (1979), 56-66.

[21] V. RADU, The fixed point alternative and the stability of functional equations, Fixed Point Theory, 4, 1 (2003), 91-96.

[22] TH. M. Rassias, On the stability of the linear mapping in Banach spaces, Proc. Amer. Math. Soc. 72 (1978), 297-300.

[23] I. A. Rus, Gronwall lemma approach to the Hyers-Ulam-Rassias stability of an integral equation, Chapter 13, Nonlinear Analysis and Variational Problems, Volume 35 of the series Springer Optimization and Its Applications.

[24] S. M. Ulam, Problems in Modern Mathematics, Chapter VI, Science Editions Wiley, New York, 1960.

[25] S. M. Ulam, A Collection of the Mathematical Problems, Interscience Publ., New York, 1960.

[26] J. WANG, Some further generalizations of the Hyers-Ulam-Rassias stability of functional equations, J. Math. Anal. Appl. 263 (2001), 406-423.

[27] X. ZHAO, Mean square Hyers-Ulam stability of stochastic differential equations driven by Brownian motion, Advances in Difference Equations (2016) 2016:271. 